\title{
Incidence of acquired thrombotic thrombocytopenic purpura in Germany: a hospital level study
}

\author{
Wolfgang Miesbach $^{1^{*}}$ (D) Jan Menne ${ }^{2}$, Martin Bommer ${ }^{3}$, Ulf Schönermarck ${ }^{4}$, Thorsten Feldkamp ${ }^{5}$, Martin Nitschke ${ }^{6}$, \\ Timm H. Westhoff ${ }^{7}$, Felix S. Seibert ${ }^{7}$, Rainer Woitas ${ }^{8}$, Rui Sousa ${ }^{9}$, Michael Wolf ${ }^{9}$, Stefan Walzer ${ }^{10}$ and \\ Björn Schwander ${ }^{11}$
}

\begin{abstract}
Background: Acquired thrombotic thrombocytopenic Purpura (aTTP) is a life-threatening ultra-orphan disease with a reported annual incidence between 1.5 and 6.0 cases per million in Europe and mainly affecting otherwise young and healthy adults aged 40 years on average. The goal of this study was to assess the incidence of aTTP in Germany.

Methods: A systematic review was performed to determine the published evidence on the aTTP epidemiology in Germany. To obtain additional evidence on the proportion of aTTP cases within the national Thrombotic Microangiopathy (TMA) population a hospital-level study was performed, using a retrospective data collection approach. Diagnosis of aTTP was confirmed if ADAMTS13 level were $<10 \%$ and/or the medical records explicitly mentioned aTTP diagnosis. The aggregated hospital data were then projected to the national level using logistic regression techniques.

Results: The systematic literature search did not provide incidence estimates of aTTP in Germany. Eight centers ( $\approx 27 \%$ of the top 30 TMA hospitals) delivered data according to a predefined data collection form. On average (year 2014-2016) a total number of 172 aTTP episodes per year was projected (95\% confidence interval [95\%Cl]: 132-212). The majority were newly diagnosed aTTP cases ( $n=121 ; 95 \% \mathrm{Cl}: 105-129)$, and 51 were recurrent aTTP cases (95\%Cl: 27-84). The average annual projected incidence (year 2014-2016) of aTTP episodes was 2.10 per million inhabitants in Germany (95\%Cl: 1.60-2.58).

Conclusions: The determined annual incidence of newly diagnosed aTTP cases and the overall annual incidence of aTTP episodes in Germany confirm the ultra-orphan character of aTTP. An external validation against international registries (France, UK and USA) shows that our findings are quite comparable with those international incidence rates.
\end{abstract}

Keywords: Epidemiology, Germany, Incidence, Thrombotic microangiopathy, Thrombotic thrombocytopenic purpura

\section{Background}

Acquired thrombotic thrombocytopenic purpura (aTTP) is a potentially life-threatening thrombotic microangiopathy resulting from systemic microvascular thrombosis and leading to profound thrombocytopenia, hemolytic anemia, and organ failure of varying severity. Acquired TTP is caused by a severe deficiency of ADAMTS13 (a disintegrin and metalloproteinase with a thrombospondin type 1

\footnotetext{
* Correspondence: wolfgang.miesbach@kgu.de

${ }^{1}$ Universitätsklinikum Frankfurt, Medizinische Klinik II / Institut für

Transfusionsmedizin und Immunhämatologie, Frankfurt, Germany

Full list of author information is available at the end of the article
}

motif, member 13) due to the presence of inhibitory autoantibodies [1]. Decreased ADAMTS13 activity leads to an accumulation of ultra large von Willebrand factor multimers, which bind to platelets and induce platelet aggregation [2].

These microthrombi cause tissue ischemia and organ dysfunction (commonly involving the brain, heart, and kidneys), resulting in early death $[3,4]$. The mortality is up to $90 \%$ if untreated, [5] and acute aTTP episodes are still associated with a mortality of $10-20 \%$ despite immediate and aggressive therapy including plasma exchange and immunosuppressive strategies [6-9]. In addition to

(c) The Author(s). 2019 Open Access This article is distributed under the terms of the Creative Commons Attribution 4.0 International License (http://creativecommons.org/licenses/by/4.0/), which permits unrestricted use, distribution, and 
the acute risks of aTTP, long-term follow-up of aTTP patients showed an increased risk of mortality and morbidity. The latter include disabling long-term consequences such as cognitive deficits, depression, and arterial hypertension, and a shortened life expectancy [8, 10-12].

aTTP is an ultra-orphan disease with a reported annual incidence between 1.5 and 6.0 cases per million (reported in French [13],US [14, 15] and UK studies [16, 17]) and mainly affecting otherwise young and healthy adults aged 40 years on average $[18,19]$. Hence, the objective of our research was to determine aTTP incidence estimates for Germany by combining different scientific approaches.

\section{Methods}

We used a stepwise model of data collection and analysis, presented in Fig. 1.

\section{Systematic literature search}

A systematic literature search, following the PRISMA (Preferred Reporting Items for Systematic Reviews and Meta-Analyses) guidelines, [20] was performed to determine the available published German evidence on the aTTP epidemiology. Details on the methodology of this systematic literature are provided as supporting information in the Additional file 1 of this manuscript.

\section{Background on national estimates}

Acquired TTP and hemolytic uremic syndrome (HUS) belong to a group of diseases known as thrombotic microangiopathies (TMAs), which present with platelet consumption, microangiopathic hemolytic anemia (MAHA) and organ dysfunction resulting from endothelial damage and microvascular thrombosis [21]. Whereas aTTP is primarily associated with central nervous system involvement and HUS is mainly seen as a disease of the kidneys, both are multi-organ diseases and may present with a quite comparable symptom complex and clinical picture, with ADAMTS13 activity as only reliable differentiation criteria [22]. Furthermore in Germany both aTTP and HUS are grouped in the same Diagnosis Related Group (DRG: L72Z named Thrombotic Microangiopathy and Hemolytic Uremic Syndrome) [23]. In Germany the tenth revision of the international classification of diseases (ICD-10) is usually used for coding purposes. As aTTP could either be coded as TMA (ICD-10 M31.1) or HUS (D59.3) national estimates on the annual frequency of both diagnoses (TMA and HUS) were determined from national hospitalization statistics [24-26], and from the German DRG (G-DRG) browser [27-29].

\section{National hospitalization statistics}

The German Federal Statistical Office provides information on the number of hospitalizations by four-digit ICD-10 main diagnosis [24-26]; there is a duty to provide information defined by the regulation on the federal statistics for hospitals, hence the hospital statistics are an annual total collection of hospitalization cases. The diagnosis data are defined and provided by the hospitals and are based on the main diagnosis at date of discharge. Data from the national hospitalization statistics were used to determine the number of cases with the primary diagnosis related to TMA (M31.1) and HUS (D59.3) per year

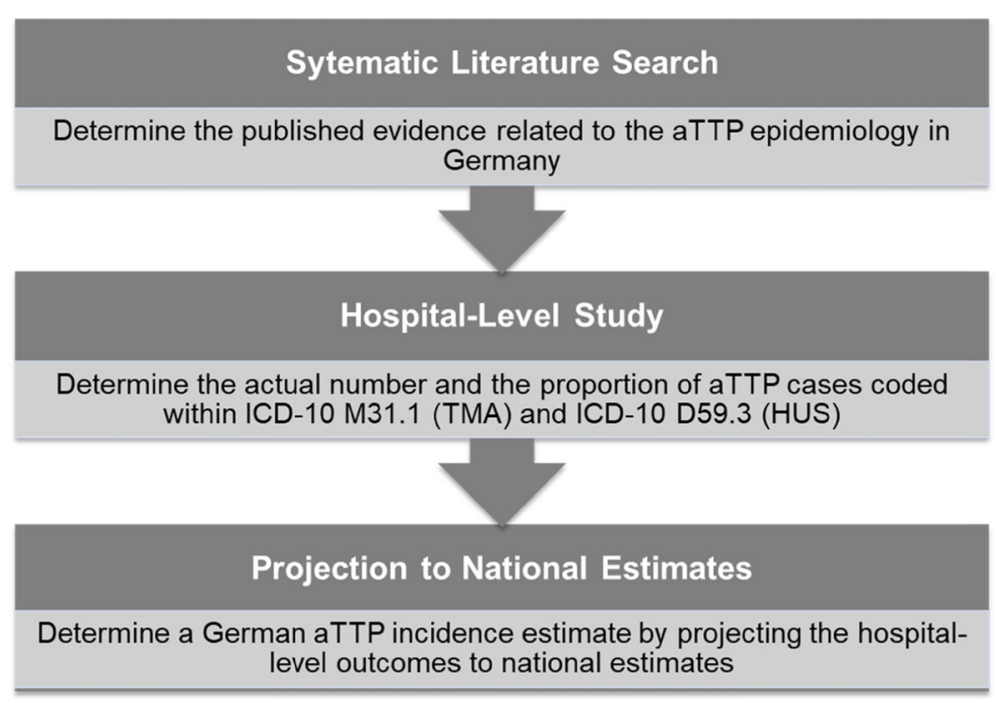

TMA=Thrombotic Microangiopathy; HUS = Hemolytic Uremic Syndrome

Fig. 1 Overview of the main research steps.TMA = Thrombotic Microangiopathy; HUS = Hemolytic Uremic Syndrome 


\section{German diagnosis related group (G-DRG) database}

The Institute for the Hospital Remuneration System (InEK; German: Institut für das Entgeltsystem im Krankenhaus) provides DRG codes and hospitalization data based on the G-DRG data delivery, according to section 21 (3) of the Hospital Remuneration Act (German: Krankenhausentgeltgesetz) [27-29]. In contrast to the national hospitalization statistics data provided by the InEK are only reflecting a subset of German hospitals $(\approx 77 \% 1500$ of 1951 hospitals for the year 2016). These data were used to determine the proportion between primary diagnosis and secondary diagnosis related to TMA (M31.1) and HUS (D59.3) per year in Germany. This proportion was then applied to the number of cases with the primary diagnosis of TMA and HUS, determined by the national hospitalization statistics, in order to estimate the number of secondary diagnosis cases for TMA and HUS in Germany

\section{Hospital-level study}

A hospital-level study was performed to determine the proportion of aTTP cases within a population of hospitalized TMA/HUS patients. To figure out the actual number and the proportion of aTTP cases coded within ICD-10 M31.1 (TMA) and ICD-10 D59.3 (HUS), a retrospective epidemiological data collection in Germany hospitals was performed. Based on the ICD-10 code descriptions, it was expected that most of the aTTP cases would be grouped within ICD M31.1 (named "Thrombotic Microangiopathy" including "Thrombotic thrombocytopenic purpura"). In order to identify the German key TMA hospitals, data from the quality reports of the hospitals (German: Qualitätsberichte der Krankenhäuser) [30], were determined as these include the number of TMA hospitalization cases (ICD-10 M31.1) on the hospital level. Using these data, the 30 German hospitals with the highest number of TMA diagnoses in 2013, 2014 and 2015 were determined, (this period refers to data used for hospital selection only) as TMA patients are usually referred to the centers of maximum care that are capable to provide all necessary TMA diagnostics and therapies. These 30 hospitals reflect mainly university hospitals and those were invited to participate in the study. Following the approval by the local ethic committees, the participating hospitals were requested to identify all hospitalization cases with the primary or secondary diagnosis of TMA (M31.1) or HUS (D59.3) recorded between 2014 and 2017, and to extract the following predefined information for each case:

- creation of a patient ID (simple consecutive Arabic case numbers in order to fulfill the requirements of anonymization and pseudonymization)
- 4-digit ICD-10 main diagnosis at the time of hospital discharge (e.g., M31.1)

- 4-digit ICD-10 secondary diagnosis at the time of discharge (only if M31.1 / D59.3)

- month and year of discharge from hospital

- ADAMTS13 activity test was performed (yes / no)

- If yes, addition of "ADAMTS13 activity in\%" (for example, 7.3\%)

- ADAMTS13 auto-antibody test was performed (yes / no)

- If "yes" the term "positive" / "negative" was added

- Existence of a known familial disposition for TTP? (Yes / No)

- further valuable information on the case (e.g. physician rating on aTTP or clarification why no ADAMTS13 test was performed, e.g. recurrent TTP or comparable information).

Patients were considered to have a confirmed diagnosis of aTTP if ADAMTS13 activity levels were $<10 \%$ and/or the medical records explicitly mentioned the diagnosis of aTTP. The differentiation between initial and recurrent aTTP episodes was performed on the basis of medical records. By applying this aTTP definition, a conservative approach was chosen as other potential approaches (e.g., ADAMTS13 activity levels < $10 \%$ as only criteria) would potentially have led to an underestimation of aTTP cases.

On the basis of these data, the number and proportions of aTTP cases within the ICD-10 M31.1 and the D59.3 (primary and secondary diagnoses at the hospital level) were determined.

\section{Projection of hospital study outcomes to national estimates}

Finally, the proportion determined in the hospital-level study was projected to the national level to elucidate an incidence of aTTP for Germany. On the basis of the outcomes of the hospital-level study, we calculated the proportion of patients with a confirmed diagnosis of aTTP for the primary and secondary diagnosis of TMA and HUS, respectively. In order to reflect the statistical uncertainty related to the hospital study sample a logistic regression analysis, in consideration of the single hospitals as a random effect measure (random effect model), was performed to reflect the $95 \%$ confidence intervals $(95 \% \mathrm{CI})$ around the mean estimates of the related proportions. These proportions and the related 95\% CIs were then applied to the national cases for TMA/HUS to project a national estimate of aTTP in Germany. Thereafter, we transferred results into an overall aTTP incidence estimate including both first and recurrent episodes of aTTP. 
The determined number of incident aTTP cases are also expressed as cases per million using the number of German inhabitants, based on data from the Federal Statistical Office, related to the year investigated. When reporting the incidence of initial (new) aTTP cases the term "incidence of aTTP" is used, whereas for the overall incidence (initial \& recurrent) of aTTP cases the term "incidence of aTTP episodes" is used.

\section{Results}

\section{Systematic literature search}

In total 340 studies were identified via the database/ journal searches, and 296 abstracts were reviewed (database/journal search minus duplicates). From these, 16 articles were selected for full-text review, and 2 papers met the inclusion criteria. The flow chart of study selection is shown in Fig. 2. Detailed information on the systematic literature search strategies' and outcomes by database / journal are provided in the supporting information (Additional file 1).

As a result of the systematic search we identified two publications [31, 32] that fulfilled all inclusion criteria, but none provided a national estimate on the aTTP incidence or prevalence for Germany. For more information on these studies please refer to the supporting information (Additional file 1).
National estimates for TMA (M31.1) and HUS (D59.3)

The national estimates for TMA and HUS primary and secondary diagnoses, which are based on the national hospitalization statistics [24-26] and on the G-DRG database [27-29], are presented in Table 1, for the years 2013 to 2016.

\section{Hospital-level study}

Eight centers $(\approx 27 \%$ of the top 30 TMA hospitals requested to participate) delivered data according to a predefined collection form. In total, during the time frame of 2014 to 2017 (hospital study data collection period), 600 hospitalization episodes related to the primary (ICDs M31.1 or D59.3 coded as primary diagnosis) or secondary diagnosis (ICDs M31.1 or D59.3 coded as secondary diagnosis) of TMA/HUS were identified and extracted. As these eight centers are major TMA centers, with a high number of TMA cases, the number of cases that were retrospectively recorded $(n=600)$ reflect approximately $10 \%$ of all German HUS / TMA cases observed in a comparable 4-year period (total $n=5906$ year 2013 to year 2016) [24-29]. The aggregated results by hospital over this four-year period are presented in Table 2.

\section{Projection of hospital study outcomes to National Estimates}

Using logistic regression analysis, the proportion of patients with a confirmed diagnosis of aTTP was calculated

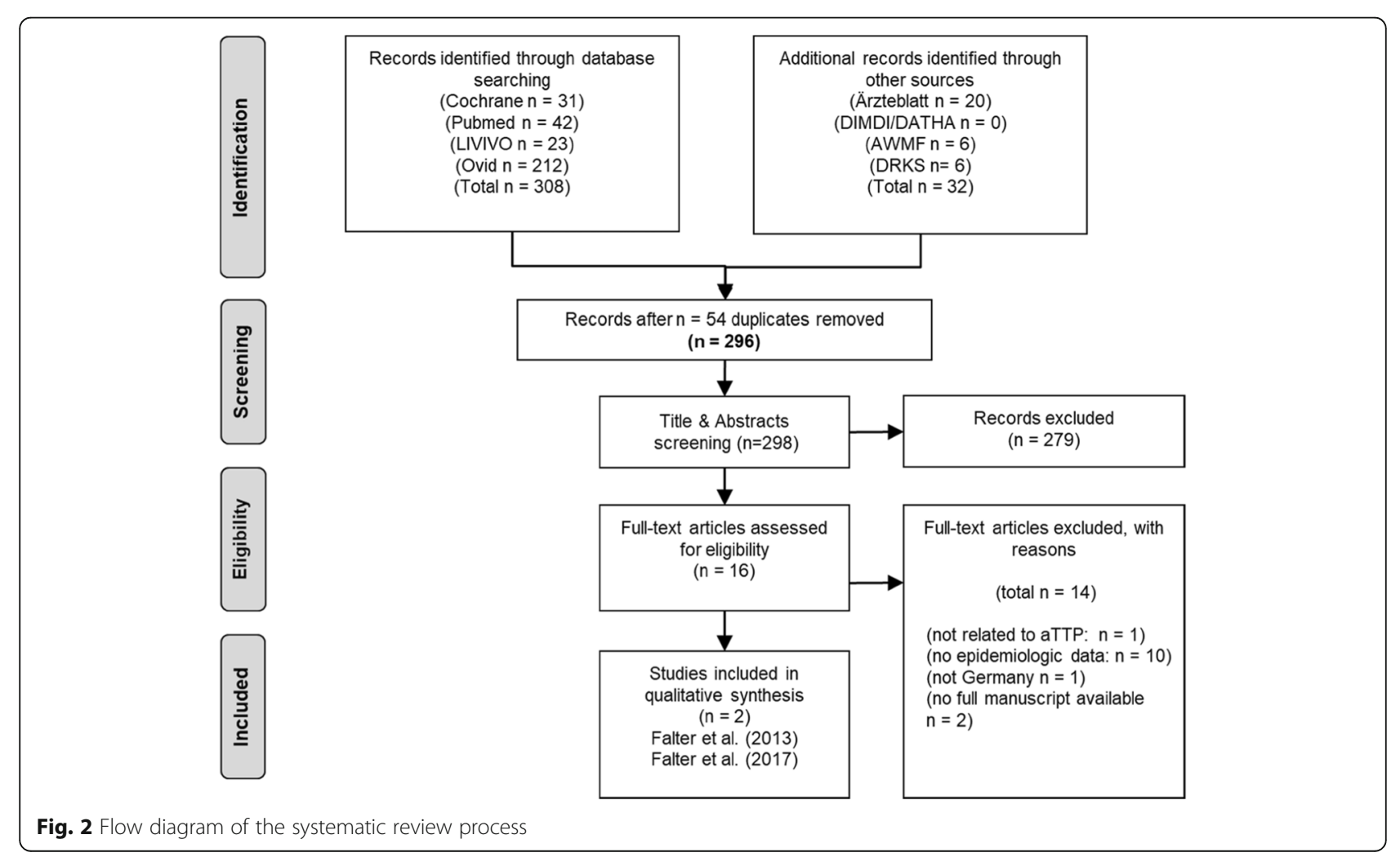


Table 1 Number of national hospitalization cases for the TMA (M31.1) and HUS (D59.3) according to primary (PD) or secondary diagnosis (SD), year of data collection and patient age

\begin{tabular}{ccccc}
\hline & Year 2016 & Year 2015 & Year 2014 & Year 2013 \\
\hline ICD-10 M31.1 TMA & & & & \\
M31.1 PD (total) & 416 & 396 & 407 & 353 \\
M31.1 PD (18+) & 403 & 381 & 394 & 336 \\
M31.1 SD (total) & 397 & 471 & 352 & 289 \\
M31.1 SD (18+) & 384 & 453 & 341 & 276 \\
ICD-10 D59.3 HUS & & & & \\
D59.3 PD (total) & 467 & 488 & 431 & 391 \\
D59.3 PD (18+) & 263 & 295 & 251 & 207 \\
D59.3 SD (total) & 267 & 294 & 273 & 214 \\
D59.3 SD (18+) & 150 & 178 & 159 & 113 \\
\hline
\end{tabular}

ICD-10 M31.1 "Thrombotic Microangiopathy", ICD-10 D59.3 "Hemolytic Uremic Syndrome", PD Primary Diagnosis, SD Secondary Diagnosis (SD), total children, adolescents and adults; $18+$ adults 18 years and older

for the primary and secondary diagnosis of TMA (M31.1) on the basis of the outcomes of the hospitallevel study. As aTTP cases were only identified in TMA patients (M31.1) the related proportion was computed only for the primary (mean 37.3\%; 95\%CI: $30.8-43.8 \%$ ) and secondary TMA (mean 5.1\%; 95\%CI: 1.7-8.6\%) diagnoses. Furthermore the proportion of recurrent aTTP cases (mean 29.9\%; 95\%CI: 20.3-39.5\%) in relation to all aTTP episodes was computed (Fig. 3).

By combining the national estimates (Table 1) and the proportion of aTTP cases, national estimates for acute aTTP episodes were calculated, which are depicted in Table 3.

Data are given for the total population (including children, adolescents and adults) and for adults only (18+). The average annual values (year 2014-2016) were 166 (95\%CI: 127-205) acute aTTP episodes projected in adults (18+) and 172 (95\%CI: 132-212) in the overall population. The majority of acute aTTP cases in the overall population occurred as initial manifestations (average annual values year 2014-2016: 121; 95\%CI: 105-129).

Using the number of inhabitants in Germany of the related years (year 2016: total: 82.50 million; 18+: 69.05; year 2015: total: 82.20 ; $18+: 68.80$; year 2014: total: 81.20 ; 18+: 67.96) [33, 34] the number of incident acute aTTP episodes (reported in Table 3) was transferred into cases per million inhabitants (Table 4). In the overall population (adults and children) the average annual incidence

Table 2 Number and proportion of aTTP cases related to all TMA (M31.1) and HUS (D59.3) hospitalization cases per participating hospital (2014-2017)

\begin{tabular}{|c|c|c|c|c|c|c|c|c|c|}
\hline Sum of Cases (2014-2017) & $M$ & HER & $\mathrm{HL}$ & $\mathrm{BN}$ & $\mathrm{F}$ & $\mathrm{Kl}$ & GP & $\mathrm{H}$ & Total \\
\hline M31.1 PD & 30 & 16 & 7 & 12 & 29 & 8 & 23 & 87 & 212 \\
\hline aTTP cases $(n)$ & 12 & 5 & 3 & 5 & 18 & 2 & 6 & $28^{*}$ & 79 \\
\hline aTTP cases $(\%)$ & $40.0 \%$ & $31.3 \%$ & $42.9 \%$ & $41.7 \%$ & $62.1 \%$ & $25.0 \%$ & $26.1 \%$ & $32.2 \%$ & $37.3 \%$ \\
\hline M31.1 SD & 36 & 21 & 9 & 15 & 13 & 28 & 0 & 34 & 156 \\
\hline aTTP cases $(n)$ & 2 & 0 & 2 & 1 & 1 & 0 & 0 & $2^{*}$ & 8 \\
\hline aTTP cases (\%) & $5.6 \%$ & $0 \%$ & $22.2 \%$ & $6.7 \%$ & $7.7 \%$ & $0.0 \%$ & $0.0 \%$ & $5.9 \%$ & $5.1 \%$ \\
\hline D59.3 PD & 8 & 0 & 23 & 14 & 15 & 8 & 7 & 65 & 140 \\
\hline aTTP cases $(n)$ & 0 & 0 & 0 & 0 & 0 & 0 & 0 & {$[1]^{*}$} & 0 \\
\hline aTTP cases (\%) & $0.0 \%$ & $0 \%$ & $0.0 \%$ & $0.0 \%$ & $0.0 \%$ & $0.0 \%$ & $0.0 \%$ & $0.0 \%$ & $0.0 \%$ \\
\hline D59.3 SD & 29 & 1 & 9 & 10 & 29 & 10 & 0 & 4 & 92 \\
\hline aTTP cases (n) & 0 & 0 & 0 & 0 & 0 & 0 & 0 & {$[1]^{*}$} & 0 \\
\hline aTTP cases (\%) & $0.0 \%$ & $0 \%$ & $0.0 \%$ & $0.0 \%$ & $0.0 \%$ & $0.0 \%$ & $0.0 \%$ & $0.0 \%$ & $0.0 \%$ \\
\hline Total cases (n) & 103 & 38 & 48 & 51 & 86 & 54 & 30 & 190 & 600 \\
\hline aTTP cases (n) & 14 & 5 & 5 & 6 & 19 & 2 & 6 & 30 & 87 \\
\hline aTTP cases (\%) & $13.6 \%$ & $13.2 \%$ & $10.4 \%$ & $11.8 \%$ & $22.1 \%$ & $3.7 \%$ & $20.0 \%$ & $15.8 \%$ & $14.5 \%$ \\
\hline Total aTTP (n) & 14 & 5 & 5 & 6 & 19 & 2 & 6 & 30 & 87 \\
\hline Recurrent aTTP (n) & 3 & 1 & 0 & 0 & 5 & 0 & 0 & 17 & 26 \\
\hline Recurrent aTTP (\%) & $21.4 \%$ & $20.0 \%$ & $0.0 \%$ & $0.0 \%$ & $26.3 \%$ & $0.0 \%$ & $0.0 \%$ & $56.7 \%$ & $29.9 \%$ \\
\hline
\end{tabular}

ICD-10 M31.1 "Thrombotic Microangiopathy", ICD-10 D59.3 "Hemolytic Uremic Syndrome", PD Primary Diagnosis, SD Secondary Diagnosis (SD), M Munich = Medical Clinic and Policlinic IV of the Ludwig-Maximilians-University Munich; HER = Herne = Marien Hospital Herne; HL = Lubeck $=$ University Hospital SchleswigHolstein, Lubeck; BN = Bonn = University Hospital Bonn; F = Frankfurt am Main = University Hospital Frankfurt; KI = Kiel = University Hospital Schleswig-Holstein, Kiel; $\mathrm{GP}=$ Göppingen = Alb Fils Kliniken $\mathrm{GmbH} ; \mathrm{H}=$ Hannover = Clinic for Kidney and Hypertension Disorders; *In Hannover, one aTTP patient was coded as D59.3 PD and one as D59.3 SD; this was identified as miscoded by the study physician; In order to adequately consider these patients, one patient each was classified as M31.1 PD and M31.1 SD and thus assigned to the correct ICD-10 coding 
(year 2014-2016) of aTTP was 1.47 (95\%CI: 1.28-1.57) and the average incidence of aTTP episodes was 2.10 (95\%CI: 1.60-2.58).

\section{Discussion}

On average (year 2014-2016) a total number of 172 aTTP episodes per year was projected (95\% confidence interval [95\%CI]: 132-212) in the German overall population (children and adults). The majority were newly diagnosed aTTP cases $(n=121$; 95\%CI: $105-129)$, and 51 were recurrent aTTP cases (95\%CI: 27-84). The related average annual aTTP incidence was 1.47 per million inhabitants (95\%CI: $1.28-1.57$ ) and the related average annual incidence of aTTP episodes was 2.10 per million inhabitants (95\%CI: 1.60-2.58). Looking at the German adult population the average annual aTTP incidence was 1.70 per million adults (95\% CI: $1.48-1.81)$ and the related average annual incidence of aTTP episodes was 2.42 per million adults (95\%CI: $1.86-3.00)$. As determined by our systematic literature search these findings represent the first national incidence estimates for aTTP in Germany.

The described projection is bound to the national estimates of TMA (ICD-M31.1) that are based on the national hospitalization statistics and on the G-DRG database [24-29], hence the available national data defined the maximum limit of the projection. Based on the hospital-level data we determined the proportion of confirmed aTTP diagnoses in primary and secondary TMA cases. To account for statistical uncertainty of the study sample, the data from the eight participating hospitals were utilized using logistic regression. This statistical uncertainty was expressed by the lower and upper $95 \% \mathrm{CI}$ around the presented incidence estimates.
As TMA and HUS are both assigned mainly to the same DRG in Germany (L72Z named Thrombotic Microangiopathy and Hemolytic Uremic Syndrome) [23], we also looked for aTTP patients coded as HUS (ICD-10 D59.3). By these means we identified two aTTP cases that were primarily miscoded as HUS (please refer to Table 2). Therefore, for the projection we considered these cases as TMA. No further aTTP cases were coded as HUS, so for the projection the national data for TMA (ICD-10 M31.1) were used as basis.

In our study, patients were considered to have a confirmed diagnosis of aTTP if ADAMTS13 activity were < $10 \%$ and/or the medical records explicitly mentioned the diagnosis of aTTP. A potential alternative definition would have been ADAMTS13 activity $<10 \%$ (as only criterion) or ADAMTS13 activity $<10 \%$ combined with a positive autoantibody (AAB) test, with the disadvantage that non-tested readmissions and borderline results (rated as aTTP) would have been excluded, both of which might have been resulted in an underestimation of the aTTP incidence.

Hence the applied definition of a confirmed diagnosis of aTTP was rated as the most reliable definition as it may deliver the most realistic estimate and no systematic underestimation on the number of aTTP cases. In $17 \%$ of cases ( $n=15$ of $n=87$ cases) there was no current ADAMTS13 activity measurement available. However, all those cases without ADAMTS13 activity measurement were classified as recurrent aTTP by the treating physician based on the clinical symptoms and by confirmed prior aTTP episodes. In further $11 \%$ patients ( $n=10$ of $n=87$ cases) the ADAMTS13 activity measurements presented borderline values (slightly above $10 \%$ ) but these were rated as aTTP by the treating physicians (e.g. as the patient had a previous aTTP episode or

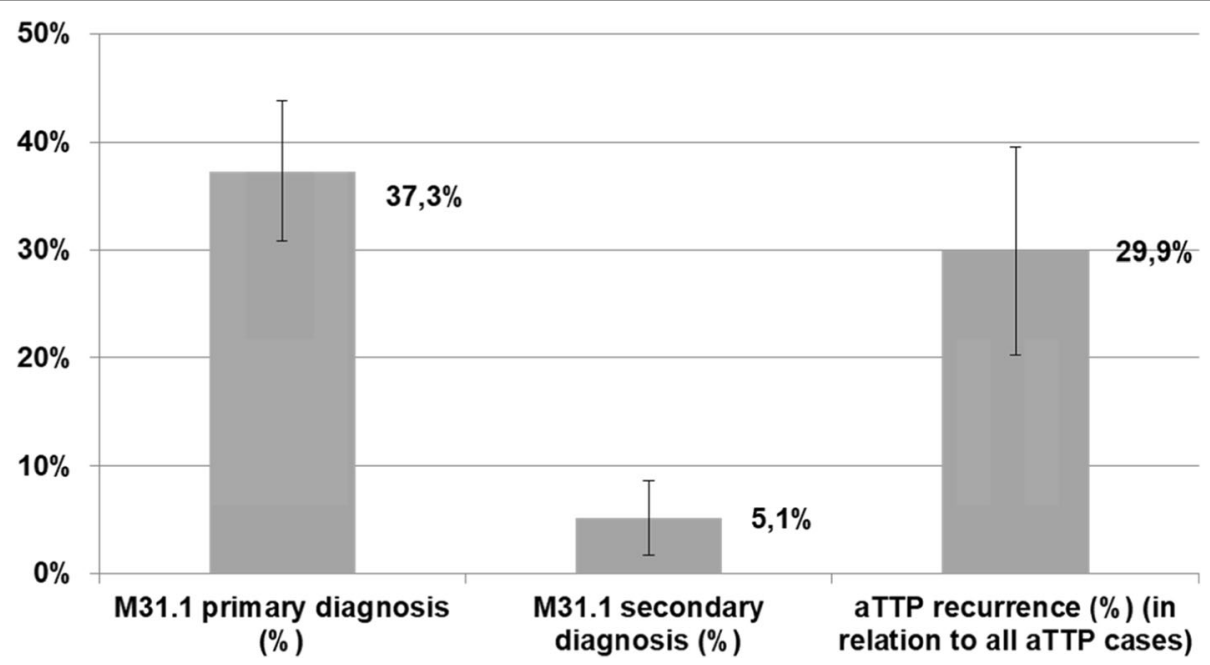

Fig. 3 fTYTA Results of the logistic regression: proportion of aTTP cases in patients with a TMA (M31.1) diagnosis based on the hospital-level study outcomes 
Table 3 Projected annual national acute aTTP cases in the overall population (total) and in adult patients (18+) related to the years 2014 to 2016

\begin{tabular}{|c|c|c|c|c|c|c|c|c|c|}
\hline \multirow[t]{2}{*}{ Projected national aTTP episodes } & \multicolumn{3}{|c|}{ Year 2016} & \multicolumn{3}{|c|}{ Year 2015} & \multicolumn{3}{|c|}{ Year 2014} \\
\hline & MV & LL 95\%Cl & UL $95 \mathrm{Cl}$ & $\mathrm{MV}$ & LL 95\%Cl & UL 95\%Cl & $\mathrm{MV}$ & LL 95\%Cl & UL 95\%Cl \\
\hline aTTP cases in M31.1 PD (total) & $155^{*}$ & 128 & 182 & 148 & 122 & 173 & 152 & 125 & 178 \\
\hline aTTP cases in M31.1 SD (total) & 20 & 7 & 34 & 24 & 8 & 40 & 18 & 6 & 30 \\
\hline Overall aTTP cases (total) & 175 & 135 & 216 & 172 & 130 & 213 & 170 & 131 & 208 \\
\hline aTTP cases (initial manifestation) (total) & 123 & 108 & 131 & 121 & 104 & 129 & 119 & 104 & 126 \\
\hline aTTP cases (recurrence) (total) & 52 & 27 & 85 & 51 & 26 & 84 & 51 & 27 & 82 \\
\hline aTTP cases in M31.1 PD (18+) & 150 & 124 & 176 & 142 & 117 & 167 & 147 & 121 & 172 \\
\hline aTTP cases in M31.1 SD (18+) & 20 & 6 & 33 & 23 & 8 & 39 & 17 & 6 & 29 \\
\hline Overall aTTP cases (18+) & 170 & 130 & 209 & 165 & 125 & 206 & 164 & 127 & 201 \\
\hline aTTP cases (initial manifestation) (18+) & 119 & 104 & 126 & 116 & 100 & 125 & 115 & 101 & 122 \\
\hline aTTP cases (recurrence) (18+) & 51 & 26 & 83 & 49 & 25 & 81 & 49 & 26 & 79 \\
\hline
\end{tabular}

*example calculation: 37.3\% (Fig. 3 M31.1 primary diagnosis $(\%)$ ) $\times 416$ cases (Table 1 M31.1 PD (total)) = 155.2 cases (rounded = 155 cases), ICD-10 M31.1 "Thrombotic Microangiopathy", PD = Primary Diagnosis, SD = Secondary Diagnosis (SD); total = children, adolescents and adults; $18+=$ adults; $\mathrm{MV}=$ mean value, $\mathrm{LL}$ $95 \% \mathrm{Cl}=$ lower limit 95\% confidence interval; UL 95\% Cl = upper limit 95\% confidence interval

as ADAMTS13 activity was measured after first plasma exchange therapy). In this context it is also of interest, that only for $59 \%$ of all study cases (351 of 600 cases) ADAMTS13 measurements were available, which explains why the ADAMTS13 activity alone was not regarded as reliable definition for the diagnosis of aTTP in the presented study.

The described approach might also include congenital TTP cases as anti-ADAMTS13 antibodies measurement was only available in $69 \%$ of patients $(n=60$ of $n=87$ cases); hence a differentiation between congenital TTP and acquired TTP, on the basis of the absence of antiADAMTS13 antibodies, was not possible in all patients. However, due to the rare event of congenital TTP forms and thorough clinical evaluation the used approach most likely has only a mild impact for overestimation of the aTTP incidence.

For better comparison of different studies detailed analysis of the used methodologies is essential. In this context it is most important to assure that only aTTP was included, whether initial and/or recurrent aTTP episodes were considered, what kind of populations (e.g. adults/children/total) were analyzed and which approach was used for the definition / diagnosis of aTTP (e.g. ADAMTS 13 activity < 10\%).

In other countries, the TTP incidence was estimated at 1.5 (France) [13], 3.1 (USA) [14], and 6.0 (UK) [16, 17] cases per million. These varying incidence rates are a result of varying definitions and of population-based differences.

Table 4 Projected annual national incidence estimates for aTTP expressed as cases per million inhabitants in the overall population (total) and in adult patients (18+) related to the years 2014 to 2016

\begin{tabular}{|c|c|c|c|c|c|c|c|c|c|}
\hline \multirow[t]{2}{*}{ Projected national aTTP episodes (per million) } & \multicolumn{3}{|c|}{ Year 2016} & \multicolumn{3}{|c|}{ Year 2015} & \multicolumn{3}{|c|}{ Year 2014} \\
\hline & MV & LL 95\%Cl & UL $95 \mathrm{Cl}$ & MV & LL 95\%Cl & UL $95 \% \mathrm{Cl}$ & MV & LL 95\%Cl & UL 95\%Cl \\
\hline aTTP cases per million in M31.1 PD (total) & $1.88^{*}$ & 1.55 & 2.21 & 1.79 & 1.47 & 2.09 & 1.87 & 1.54 & 2.19 \\
\hline aTTP cases per million in M31.1 SD (total) & 0.24 & 0.08 & 0.41 & 0.29 & 0.10 & 0.48 & 0.22 & 0.07 & 0.37 \\
\hline Overall aTTP cases per million (total) & 2.12 & 1.63 & 2.62 & 2.08 & 1.57 & 2.57 & 2.09 & 1.61 & 2.56 \\
\hline aTTP cases per million (initial) (total) & 1.49 & 1.31 & 1.59 & 1.46 & 1.26 & 1.56 & 1.47 & 1.28 & 1.55 \\
\hline aTTP cases per million (recurrence) (total) & 0.63 & 0.32 & 1.03 & 0.62 & 0.31 & 1.01 & 0.62 & 0.33 & 1.01 \\
\hline aTTP cases per million in M31.1 PD (18+) & 2.17 & 1.80 & 2.55 & 2.06 & 1.70 & 2.43 & 2.16 & 1.78 & 2.53 \\
\hline aTTP cases per million cases in M31.1 SD (18+) & 0.29 & 0.09 & 0.48 & 0.33 & 0.12 & 0.57 & 0.25 & 0.09 & 0.43 \\
\hline Overall aTTP cases per million (18+) & 2.46 & 1.89 & 3.03 & 2.39 & 1.82 & 3.00 & 2.41 & 1.87 & 2.96 \\
\hline aTTP cases per million (initial) (18+) & 1.72 & 1.51 & 1.82 & 1.69 & 1.45 & 1.82 & 1.69 & 1.49 & 1.80 \\
\hline aTTP cases per million (recurrence) (18+) & 0.74 & 0.38 & 1.21 & 0.70 & 0.37 & 1.18 & 0.72 & 0.38 & 1.16 \\
\hline
\end{tabular}

* example calculation: 155 cases (Table 3 aTTP cases in M31.1 in 2016) per 82.5 million inhabitants in $2016=1.88$ acute aTTP cases per million, ICD-10 M31.1 "Thrombotic Microangiopathy", PD = Primary Diagnosis, SD = Secondary Diagnosis (SD); total = children, adolescents and adults; $18+=$ adults; MV = mean value, LL $95 \% \mathrm{Cl}=$ lower limit $95 \%$ confidence interval; UL $95 \% \mathrm{Cl}=$ upper limit $95 \%$ confidence interval 
The data from the French registry were calculated on the basis of a large cohort, which was enrolled in the registry over 15 years. They only included patients with a first TMA episode and an ADAMTS13 activity $<10 \%$ which was measured in one reference center with a highly standardized method. Therefore the quality of the results can be considered as very reliable. Looking at the applied methods the comparison of our approach to the French cohort seems to be reasonable with the difference that we also report the incidence of recurrent aTTP episodes, while the French group reports only the incidence of (initial) aTTP. Comparing the results we show a good accordance, as in our projection for Germany 1.47 per million inhabitants ( 1.5 per million in France) are estimated to have an initial aTTP manifestation. In adults the related incidence of aTTP is 1.70 per million.

In the UK TTP registry the incidence of TTP episodes was calculated on the basis of a clinical diagnosis according to national guidelines [35], excluding other conditions such as HUS and HELLP, but patients with secondary TTP (e.g. due to HIV infection or druginduced TTP) were included $[16,17]$. As this approach did not rely on ADAMTS13 measurement, the real incidence of aTTP might have been overestimated in the UK study.

In the United States the Oklahoma TTP-HUS registry provides estimates for the incidence of initial and recurrent aTTP in a mixed population (adult and children), allowing a good comparison to our assessment. Reese et al. reported a standardized aTTP incidence rate (newly diagnosed cases) of 2.17 (95\%CI: 2.00-2.34) per million observed in the Oklahoma TTP-HUS registry [14], compared to 1.47 (95\%CI: $1.28-1.57)$ ) per million population in our study. Page et al. Identified a combined incidence of initial and recurrent aTTP episodes of 3.1 per million [15] as compared to 2.10 per million inhabitants (95\%CI: 1.60-2.58) identified in the present study. The slightly lower incidence found in our study in our study could be explained with the predominant Caucasian origin of the German population in contrast to the Oklahoma registry. As the aTTP incidence was found to be higher in the black population compared to non-blacks (Incidence rate ratio 7.09), [14] this might explain the higher incidence observed in the Oklahoma registry.

Besides the aspects that were already discussed above, there are further limitations of our study. Our incidence estimate is reflecting a mainly Caucasian population and only eight of thirty invited hospitals provided retrospective data and were hence included into this study. Centers from the North, West and South of Germany were equally represented, with a lack of centers from the eastern parts of Germany. As these eight centers are major TMA centers the number of cases that were retrospectively recorded $(n=600)$ reflects approximately $10 \%$ of all German HUS / TMA cases $(n=5906)$ [24-29] in this period. With regard to the patient numbers (based on the primary TMA diagnosis) the participating centers reflect about $25 \%$ of patients in all top 30 TMA hospitals. However, the logistic regression analysis of the hospital-level data helps to describe potential inaccuracies with $95 \%$ confidence intervals.

A further limitation is that we have only selected major TMA centers as basis for our assessment. It is difficult to predict, but possible, that the inclusion of smaller centers (outside the top 30) might have altered the proportion of aTTP cases in relation to all TMA hospitalization cases. However, as our findings compare well to the findings of the French [13] and the Oklahoma [14] aTTP registry, the impact of this potential selection bias is rated minor.

\section{Conclusions}

The determined average annual incidence of newly diagnosed aTTP cases (1.47 per million inhabitants; 1.70 per million adults) and the overall average annual incidence of aTTP episodes (2.10 per million inhabitants and 2.42 per million adults, respectively) in Germany confirm the ultra-orphan character of aTTP. An external validation against international registries (France, UK and USA) shows that our findings are quite comparable with those international incidence rates.

\section{Additional file}

Additional file 1. Protocol and results of systematic literature search on German epidemiology data about thrombotic thrombocytopenic purpura (TTP).

\section{Abbreviations}

AAB: Autoantibody; ADAMTS13: A disintegrin and metalloproteinase with a thrombospondin type 1 motif, member 13; aTTP: Acquired thrombotic thrombocytopenic purpura; Cl: Confidence interval; DRG: Diagnosis related group; G-DRG: German diagnosis related group; HUS: Hemolytic uremic syndrome; ICD-10: International classification of diseases - tenth revision; InEK: Institute for the hospital remuneration system; German: Institut für das Entgeltsystem im Krankenhaus; MAHAT: Microangiopathic hemolytic anemia and thrombocytopenia; PRISMA: Preferred reporting items for systematic reviews and meta-analyses; TMA: Thrombotic Microangiopathy

\section{Acknowledgements}

Not applicable

\section{Authors' contributions}

WM: data retrieval, interpretation of data, review and feedback on manuscript draft(s); approval of the submitted version. JM: data retrieval, interpretation of data, review and feedback on manuscript draft(s); approval of the submitted version. MB: data retrieval, interpretation of data, review and feedback on manuscript draft(s); approval of the submitted version. US: data retrieval, interpretation of data, review and feedback on manuscript draft(s); approval of the submitted version. TF: data retrieval, interpretation of data, review and feedback on manuscript draft(s); approval of the submitted version. MN: data retrieval, interpretation of data, review and feedback on manuscript draft(s); approval of the submitted version. TW: data retrieval, interpretation of data, review and feedback on manuscript draft(s); approval of the submitted version. FS: data retrieval, interpretation of data, review and 
feedback on manuscript draft(s); approval of the submitted version. RW: data retrieval, interpretation of data, review and feedback on manuscript draft(s); approval of the submitted version. RS: initiated the study, interpreted the data and supported the development of the manuscript, review and feedback on manuscript draft(s); approval of the submitted version. MW: initiated the study, interpreted the data and supported the development of the manuscript, review and feedback on manuscript draft(s); approval of the submitted version. SW: designed the study, interpreted the data and supported the development of the manuscript, review and feedback on manuscript draft(s); approval of the submitted version. BS: designed, initiated, managed and analyzed the hospital study, performed the systematic review and supported the development of the manuscript, review and feedback on manuscript draft(s); approval of the submitted version.

\section{Funding}

This study was financed by Ablynx a Sanofi Company. As also presented in the author contribution section employees from Ablynx a Sanofi Company (Dr. Sousa and Mr. Wolf) were involved in the design of the study, the interpretation of data and in supporting the development of the manuscript.

\section{Availability of data and materials}

All data generated or analyzed during this study were included in this published article [and its supplementary information files].

\section{Ethics approval and consent to participate}

All human studies have been approved by the appropriate ethics committee and have therefore been performed in accordance with the ethical standards laid down in the 1964 Declaration of Helsinki and its later amendments.

Lead ethic committee approval by $\mathrm{MHH}$ (Medizinische Hochschule Hannover) - reference \# 7773_BO_K_2018 (dated 14.02.2018) - each individual hospital requested ethic approval at the responsible local committees - on the basis of the lead ethic committee approval. Retrospective data collection approach based on anonymized data (no informed consent was necessary).

\section{Consent for publication}

Not applicable

\section{Competing interests}

WM: Prof. Miesbach reports personal fees from Ablynx a Sanofi Company, during the conduct of the study; personal fees from Ablynx a Sanofi Company, personal fees from Shir, outside the submitted work. JM: Prof. Menne reports personal fees from Ablynx a Sanofi Company, during the conduct of the study; personal fees from Ablynx a Sanofi Company, personal fees from Sanofi Genzyme, personal fees from Alexion, outside the submitted work.

MB: Dr. Bommer reports personal fees from Ablynx a Sanofi Company, during the conduct of the study; personal fees from Ablynx a Sanofi Company, personal fees from Sanofi, personal fees from Alexion, outside the submitted work.

US: Dr. Schönermarck reports personal fees from Ablynx a Sanofi Company, during the conduct of the study; personal fees from Ablynx a Sanofi Company, personal fees from Alexion, outside the submitted work. TF: Prof. Feldkamp reports personal fees from Ablynx a Sanofi Company, during the conduct of the study; personal fees from Ablynx a Sanofi Company, personal fees from Akari, personal fees from Alexion, outside the submitted work

MN: Dr. Nitschke reports personal fees from Alexion, outside the submitted work.

TW: Prof. Westhoff has nothing to disclose

FS: Dr. Seibert has nothing to disclose.

RW: Prof. Woitas has nothing to disclose.

RS: Dr. Sousa reports personal fees from Ablynx a Sanofi Company, during the conduct of the study; personal fees from Ablynx a Sanofi Company, outside the submitted work.

MW: Mr. Wolf reports personal fees from Ablynx a Sanofi Company, during the conduct of the study; personal fees from Ablynx a Sanofi Company, outside the submitted work.
SW: Dr. Walzer reports personal fees from Ablynx a Sanofi Company, during the conduct of the study; personal fees from Ablynx a Sanofi Company, outside the submitted work

BS: Mr. Schwander reports personal fees from Ablynx a Sanofi Company, during the conduct of the study; personal fees from Ablynx a Sanofi Company, outside the submitted work.

\section{Author details}

${ }^{1}$ Universitätsklinikum Frankfurt, Medizinische Klinik II / Institut für Transfusionsmedizin und Immunhämatologie, Frankfurt, Germany. ${ }^{2}$ Medizinische Hochschule Hannover, Klinik für Nieren- und Hochdruckerkrankungen, Hannover, Germany. ${ }^{3}$ Alb-Fils Kliniken Göppingen, Klinik für Hämatologie, Onkologie und Infektionskrankheiten, Göppingen, Germany. ${ }^{4}$ Klinikum der Universität München - Medizinische Klinik und Poliklinik IV, Nephrologisches Zentrum, München, Germany. ${ }^{5}$ Klinik für Innere Medizin IV - Universitätsklinikum Schleswig Holstein, Nieren- und Hochdruckkrankheiten, Kiel, Germany. ${ }^{6}$ Medizinische Klinik I Universitätsklinikum Schleswig Holstein, Nephrologie \& Transplantation Lübeck, Germany. ${ }^{7}$ Medizinische Klinik I - Universitätsklinikum Marien Hospital Herne, Ruhr-Universität Bochum, Herne, Germany. ${ }^{8}$ Medizinische Klinik und Poliklinik I - Universitätsklinikum Bonn, Bonn, Germany. ${ }^{9}$ Ablynx a Sanofi Company, Medical Affairs, Zwijnaarde, Belgium. ${ }^{10}$ MArS - Market Access \& Pricing Strategy GmbH, Weil am Rhein, Germany. ${ }^{11}$ AHEAD GmbH, Agency for Health Economic Assessment and Dissemination, Lörrach, Germany.

Received: 4 July 2019 Accepted: 29 October 2019

Published online: 15 November 2019

\section{References}

1. Sadler JE. Von Willebrand factor, ADAMTS13, and thrombotic thrombocytopenic purpura. Blood. 2008;112(1):11-8.

2. Sarig G. ADAMTS-13 in the diagnosis and management of thrombotic microangiopathies. Rambam Maimonides Med J. 2014;5(4):e0026.

3. Patschan D, Witzke O, Duhrsen U, Erbel R, Philipp T, Herget-Rosenthal S. Acute myocardial infarction in thrombotic microangiopathies--clinical characteristics, risk factors and outcome. Nephrol Dial Transplant. 2006;21(6): 1549-54.

4. Nichols L, Berg A, Rollins-Raval MA, Raval JS. Cardiac injury is a common postmortem finding in thrombotic thrombocytopenic purpura patients: is empiric cardiac monitoring and protection needed? Ther Apher Dial. 2015; 19(1):87-92.

5. Goel R, King KE, Takemoto CM, Ness PM, Tobian AA. Prognostic risk-stratified score for predicting mortality in hospitalized patients with thrombotic thrombocytopenic purpura: nationally representative data from 2007 to 2012. Transfusion. 2016:56(6):1451-8.

6. Benhamou Y, Assie C, Boelle PY, Buffet M, Grillberger R, Malot S, et al. Development and validation of a predictive model for death in acquired severe ADAMTS13 deficiency-associated idiopathic thrombotic thrombocytopenic purpura: the French TMA reference center experience. Haematologica. 2012;97(8):1181-6.

7. Kremer Hovinga JA, Vesely SK, Terrell DR, Lammle B, George JN. Survival and relapse in patients with thrombotic thrombocytopenic purpura. Blood. 2010; 25;115(8):1500-11.

8. Deford CC, Reese JA, Schwartz LH, Perdue JJ, Kremer Hovinga JA, Lammle B, et al. Multiple major morbidities and increased mortality during long-term follow-up after recovery from thrombotic thrombocytopenic purpura. Blood. 2013;122(12):2023-9.

9. Veseley SK. Life after acquired thrombotic thrombocytopenic purpura: morbidity, mortality, and risks during pregnancy. J Thromb Haemost. 2015; 13(suppl 1):S216-S22.

10. Lewis QF, Lanneau MS, Mathias SD, Terrell DR, Vesely SK, George JN. Longterm deficits in health-related quality of life after recovery from thrombotic thrombocytopenic purpura. Transfusion. 2009;49(1):118-24.

11. Han B, Page EE, Stewart LM, Deford CC, Scott JG, Schwartz LH, et al. Depression and cognitive impairment following recovery from thrombotic thrombocytopenic purpura. Am J Hematol. 2015;90(8):709-14.

12. Kennedy AS, Lewis QF, Scott JG, Kremer Hovinga JA, Lammle B, Terrell DR, et al. Cognitive deficits after recovery from thrombotic thrombocytopenic purpura. Transfusion. 2009;49(6):1092-101. 
13. Veyradier A, editor PTT: épidémiologie de la cohorte du CNR-MAT sur 16 ans. Compte rendu de la 8è réunion du CNR-MAT; 2015 10/16/2015; Paris2015.

14. Reese JA, Muthurajah DS, Kremer Hovinga JA, Vesely SK, Terrell DR, George $\mathrm{JN}$. Children and adults with thrombotic thrombocytopenic purpura associated with severe, acquired Adamts13 deficiency: comparison of incidence, demographic and clinical features. Pediatr Blood Cancer. 2013; 60(10):1676-82.

15. Page EE, Kremer Hovinga JA, Terrell DR, Vesely SK, George JN. Thrombotic thrombocytopenic purpura: diagnostic criteria, clinical features, and longterm outcomes from 1995 through 2015. Blood Adv. 2017;1 (10):590-600.

16. Scully M, Yarranton H, Liesner R, Cavenagh J, Hunt B, Benjamin S, et al. Regional UK TTP registry: correlation with laboratory ADAMTS 13 analysis and clinical features. Br J Haematol. 2008;142(5):819-26.

17. Hassan S, Westwood JP, Ellis D, Laing C, Mc GS, Benjamin S, et al. The utility of ADAMTS13 in differentiating TTP from other acute thrombotic microangiopathies: results from the UK TTP registry. Br J Haematol. 2015; 171(5):830-5.

18. Terrell DR, Williams LA, Vesely SK, Lammle B, Hovinga JA, George JN. The incidence of thrombotic thrombocytopenic purpura-hemolytic uremic syndrome: all patients, idiopathic patients, and patients with severe ADAMTS-13 deficiency. J Thromb Haemost. 2005;3(7):1432-6.

19. Miller DP, Kaye JA, Shea K, Ziyadeh N, Cali C, Black C, et al. Incidence of thrombotic thrombocytopenic purpura/hemolytic uremic syndrome. Epidemiology. 2004;15(2):208-15.

20. Moher D, Liberati A, Tetzlaff J, Altman DG. Preferred reporting items for systematic reviews and meta-analyses: the PRISMA statement. Ann Intern Med. 2009:151(4):264-9 w64.

21. Scully M, Cataland S, Coppo P, de la Rubia J, Friedman KD, Kremer HJ, et al. Consensus on the standardization of terminology in thrombotic thrombocytopenic purpura and related thrombotic microangiopathies. J Thromb Haemost. 2017;15(2):312-22.

22. Matsumoto M, Fujimura Y, Wada H, Kokame K, Miyakawa $Y$, Ueda Y, et al. Diagnostic and treatment guidelines for thrombotic thrombocytopenic purpura (TTP) 2017 in Japan. Int J Hematol. 2017;106(1):3-15.

23. InEK GmbH. Fallpauschalen-Katalog, G-DRG-Version 2018 [Available from: https://www.g-drg.de/content/download/7387/55403/version/1/file/ Fallpauschalen_Katalog_2018_171124.pdf.

24. Statistisches B. Tiefgegliederte Diagnosedaten der Krankenhauspatientinnen und -patienten 20142015 [Available from: https://www.destatis.de/DE/ Publikationen/Thematisch/Gesundheit/Krankenhaeuser/ TiefgegliederteDiagnosedaten.htm.

25. Statistisches B. Tiefgegliederte Diagnosedaten der Krankenhauspatientinnen und -patienten 2015. (Auszug aus Excel-Tabelle mit relevanten Daten) 2016 [Available from: https://www.destatis.de/DE/Publikationen/Thematisch/ Gesundheit/Krankenhaeuser/TiefgegliederteDiagnosedaten.htm.

26. Statistisches B. Tiefgegliederte Diagnosedaten der Krankenhauspatientinnen und -patienten 2016. (Auszug aus Excel-Tabelle mit relevanten Daten) 2017 [Available from: https://www.destatis.de/DE/Publikationen/Thematisch/ Gesundheit/Krankenhaeuser/TiefgegliederteDiagnosedaten.htm.

27. InEK GmbH. G-DRG-Browser 2014_2015 2016 [Available from: https://www g-drg.de/inek_site_de/layout/set/einspaltig/Media/Files/Datenbereitstellung/ G-DRG-Browser_2014_2015_Zip.

28. InEK GmbH. G-DRG-Browser 2015_2016 2017 [Available from: https://www g-drg.de/Datenbrowser_und_Begleitforschung/Datenveroeffentlichung_ gem._21_KHEntgG/G-DRG-Browser_2015_2016.

29. InEK GmbH. G-DRG-Report-Browser 20172017 [Available from: http://www. g-drg.de/Datenbrowser_und_Begleitforschung/G-DRG-Report-Browser/GDRG-Report-Browser_2017.

30. Gemeinsamer B. Qualitätsberichte der Krankenhäuser in maschinenverwertbarer Form 2013-2015 2018 [updated 25.07.2018. Available from: https://www.g-ba.de/institution/themenschwerpunkte/ qualitaetssicherung/qualitaetsdaten/qualitaetsbericht/xml-daten/.

31. Falter $T$, Schmitt $V$, Herold S, Weyer V, von Auer C, Wagner S, et al. Depression and cognitive deficits as long-term consequences of thrombotic thrombocytopenic purpura. Transfusion. 2017;57(5):1152-62.

32. Falter T, Alber KJ, Scharrer I. Long term outcome and sequelae in patients after acute thrombotic thrombocytopenic purpura episodes. Hamostaseologie. 2013;33(2):113-20.

33. Statistisches B. Zensus 2011 - Bevölkerung am 9. Mai 2011 - Anteil Bevölkerung unter 18 Jahren 2011 [Available from: https://www.destatis.de/
DE/PresseService/Presse/Pressekonferenzen/2013/Zensus2011/ bevoelkerung_zensus2011.pdf;jsessionid=6EFE8209B0561B11F7D6E5D2DA1 AD597.InternetLive1?__blob=publicationFile.

34. Statistisches B. Bevölkerungsstand - Bevölkerung nach Altersgruppen, Familienstand und Religionszugehörigkeit 2018 [Available from: https:// www.destatis.de/DE/ZahlenFakten/GesellschaftStaat/Bevoelkerung/ Bevoelkerungsstand/Tabellen/AltersgruppenFamilienstandZensus.html.

35. Allford SL, Hunt BJ, Rose P, Machin SJ. Guidelines on the diagnosis and management of the thrombotic microangiopathic haemolytic anaemias. $\mathrm{Br}$ J Haematol. 2003;120(4):556-73.

\section{Publisher's Note}

Springer Nature remains neutral with regard to jurisdictional claims in published maps and institutional affiliations.
Ready to submit your research? Choose BMC and benefit from:

- fast, convenient online submission

- thorough peer review by experienced researchers in your field

- rapid publication on acceptance

- support for research data, including large and complex data types

- gold Open Access which fosters wider collaboration and increased citations

- maximum visibility for your research: over $100 \mathrm{M}$ website views per year

At BMC, research is always in progress.

Learn more biomedcentral.com/submissions 